\title{
The Independent Payment Advisory Board
}

\author{
J.A. Hirsch, W.D. Donovan, R.M. Barr, G.N. Nicola, D.A. Rosman, P.W. Schaefer, and L. Manchikanti
}

ABBREVIATIONS: IPAB = Independent Payment Advisory Board; $\mathrm{ACA}=$ Patient Protection and Affordable Care Act; PCORI $=$ Patient Centered Outcomes Research Institute; MedPAC $=$ Medicare Payment Advisory Commission

$\mathbf{T}$ he Independent Payment Advisory Board (IPAB) is considered the most potent cost-cutting measure of the Patient Protection and Affordable Care Act (ACA), which was signed into law in March 2010. Together with the Patient Centered Outcomes Research Institute (PCORI), it is 1 of 2 independent boards established as part of the sweeping health care reform bill and is one of the bill's most controversial measures.

The IPAB, when complete, will be composed of 15 members charged with holding Medicare spending growth within specified limits. Whenever projected Medicare spending exceeds determined target levels, the IPAB is required to present recommendations to control costs, and the Health and Human Services Secretary is required to implement those changes unless Congress specifically takes action to override the recommendations and replace them with alternatives that achieve similar savings.

Neuroradiologists should be informed about the existence and purpose of the IPAB because their reimbursement may be significantly affected by its actions in the foreseeable future.

The Affordable Care Act represents a generational change in the provision of health care in the United States. ${ }^{1-3}$ It includes a monumental expansion of Medicaid as well as the development of a system of State-Based Health Insurance Exchanges for those citizens who do not qualify for the expanded Medicaid system. There are mandates for people to purchase insurance and for businesses to provide insurance to avoid penalties. To help fund this expansion, there are reductions in funding for programs such as Medicare Advantage; and there are new tax programs, such as

From the Department of Radiology (J.A.H., D.A.R., P.W.S.), Massachusetts General Hospital, 55 Fruit St, Gray Bldg., 2nd Floor, Boston, Massachusetts; Norwich Diagnostic Imaging Associates (W.D.D.), Norwich, Connecticut; Mecklenburg Radiology Associates (R.M.B.), Charlotte, North Carolina; Hackensack University Medical Center (G.N.N.), Hackensack, New Jersey; Pain Management Center of Paducah (L.M.), Paducah, Kentucky; and University of Louisville (L.M.), Louisville, Kentucky. All authors contributed equally to the preparation of the manuscript.

Please address correspondence to: Joshua A. Hirsch, Department of Radiology, Massachusetts General Hospital, 55 Fruit St, Gray Bldg., 2nd Floor, Boston, MA 02114; e-mail: Hirsch@snisonline.org

http://dx.doi.org/10.3174/ajnr.A3736 the Medicare Tax Rate Increase, the Net Investment Income Tax, and the Cadillac Insurance Tax. ${ }^{2-4}$

The ACA is divided into 10 titles with elements that went into effect as early as June 21, 2010. ${ }^{1-3,5}$ There have been multiple attempts by House Republicans to revoke this law. ${ }^{6}$ Although small portions of the law have been enforced since the passage of the ACA, 2014 and 2015 will mark the implementation of some of its principal components. ${ }^{4,5,7,8}$

Two independent boards have been established as part of the law. The first is the Patient Centered Outcomes Research Institute. PCORI moves the agenda of comparative effectiveness research forward; given the limited work that has been done in this area, PCORI provides an opportunity for neuroradiologists to obtain funding to investigate practices that will improve patient care. ${ }^{8}$ Its formation has enjoyed the support of the American College of Radiology, as well as much of organized medicine, though there are notable exceptions. ${ }^{8,9}$ As part of the legislation, PCORI cannot be used for denial of coverage nor may it consider the cost of providing care. ${ }^{2,8,9,10}$

The second of the 2 boards is the Independent Payment Advisory Board. As opposed to PCORI, IPAB has drawn criticism from much of organized medicine, including the American College of Radiology and the American Society of Neuroradiology. The raison d'être for the IPAB is to facilitate statutory Medicare budget limits. ${ }^{7}$ This vignette will focus on the IPAB.

\section{HISTORY}

During the administration of President Lyndon B. Johnson, Congress created Medicare as part of a series of social reforms known as the "Great Society." This landmark legislation occurred in 1965 as part of Title XVIII of the Social Security Act. Its purpose was to provide health insurance to people age 65 years and older, regardless of income or medical history.

The growth in cost during the past 45 years of the US health care endeavor, including Medicare, has been striking. ${ }^{5,10}$ In 2011, total US health care spending was $\$ 2.7$ trillion; this represented $17.9 \%$ of gross domestic product, the highest percentage of any 
industrialized nation. The average industrialized nation spends $9.5 \%$ of gross domestic product on health care. The countries with the second and third highest percentages are the Netherlands at $12 \%$, and France at $11.6 \%$ (2010 Organisation for Economic Cooperation and Development Health Data, reported in 2012). Most agree that this trend is unsustainable. ${ }^{11}$

Recent publications ${ }^{11,12}$ have documented a slowing of growth in US health care spending. In 2011, US health care spending grew 3.9\%, marking the third consecutive year of relatively slow growth. Growth in national health spending closely tracked growth in nominal gross domestic product in 2010 and 2012, and health spending as a share of gross domestic product remained stable from 2009 through 2011. However, although growth in spending at the national level has remained stable, personal health care spending growth accelerated in 2011 from $3.7 \%-4.1 \%$, in part because of faster growth in spending for prescription drugs and physician and clinical services. A recent Medicare trustees report ${ }^{13}$ postulated with cautious optimism that the slowdown in health spending that has extended the trust fund's life is here to stay, and not a reflection of the slow economy of the past few years. However, in this estimation, it was assumed that the Sustainable Growth Rate cuts would be implemented. If the Sustainable Growth Rate were replaced, this would likely increase costs of Medicare and more rapidly deplete the Medicare trust fund. ${ }^{7,13,14}$

During the years there have been a variety of proposals to create an independent entity, analogous to the United Kingdom's National Institute for Health and Clinical Excellence of the National Health Service, that would be charged with curbing growth in federal health care spending. ${ }^{15}$ Theoretically, this independent status would insulate these policy makers from special-interest groups and lobbyists. ${ }^{15-17}$

Along those lines, the IPAB is an independent board within the executive branch. This is in direct contrast to the Medicare Payment Advisory Commission (MedPAC), an existing panel that reports to the legislative branch. ${ }^{1-3,7,8}$ MedPAC was enacted as part of the Balanced Budget Act of 1997 by merger of the Prospective Payment Assessment Commission and the Physician Payment Review Commission. ${ }^{18}$ Composed of 17 appointed members, it generates 2 formal reports per year to Congress on policy and payment issues affecting Medicare.

However, MedPAC's role is purely advisory; Congress has frequently declined to follow its recommendations.

The IPAB is composed of 15 full-time members to be appointed by the President, and approved by the Senate. As most of the members are required to be nonproviders, as mandated by the legislation, Board membership is a full-time job so as to limit any possibility of conflict of interest.

The IPAB would have the authority to make both mandatory and advisory recommendations.

\section{IPAB RECOMMENDATIONS}

The IPAB is mandated to submit recommendations whenever Medicare per capita spending growth is projected to exceed statutory targets. The timelines are defined in the legislation. ${ }^{5,19}$ The recommendation requires an explanation and rationale, as well as an estimate of the necessary administrative funding. The Center for Medicare \& Medicaid Services Actuary must certify that the recommendations will result in the legislatively mandated savings and will not result in any increase in Medicare spending during the subsequent 10 -year period starting with the implementation year.

In addition to the mandatory recommendations above, the IPAB can make advisory recommendations on far-ranging health care policy issues, including recommendations to slow the growth of private health care expenditures-much like MedPAC.

As part of a common theme of the ACA (ie, more care at less cost), the mandatory recommendations are required to maintain or enhance beneficiary access to quality care. Moreover, the law prohibits certain recommendations that could negatively affect beneficiaries or certain providers. The IPAB may not recommend anything that could be construed as rationing health care, increase Medicare beneficiary costs, or otherwise restrict benefits.

\section{FAST-TRACK PROCEDURES}

The extraordinary powers of the IPAB, in part, derive from unique congressional fast-track procedures for its mandatory recommendations. The board's proposals must be introduced to both the House and the Senate on the same day. Once introduced, these mandatory recommendations must be sent to the committees with relevant jurisdiction. The committees must report those recommendations, with any changes, within 3 months, or the proposals are formally discharged from the committees. Of note, the committees and the full House and Senate cannot consider any amendment that would change or repeal the IPAB's recommendations unless those changes meet the same fiscal criteria under which the board operates. A supermajority in the Senate is required to waive this restriction.

\section{LIMITATIONS ON JUDICIAL OR ADMINISTRATIVE REVIEW}

In addition to the severe constraints placed on Congress, the ACA explicitly disallows review by either the administration or the judiciary. Although this move sounds aggressive, it is in keeping with the policy goal of moving forward with the mandatory recommendations of the IPAB. Specifically, the Secretary of Health and Human Services is required to implement the IPAB recommendations, or an alternative of a similar revenue-saving effect.

\section{DISCUSSION}

The ACA represents a paradigm shift in how health care will be delivered for millions of Americans. ${ }^{1-3}$ Its key programs of mandated insurance, elimination of pre-existing conditions, and children's coverage until age 26 years have been widely reviewed.

Less known to the broad audience who has interest in the ACA are the particulars of the IPAB. ${ }^{1-3,7,8}$ The IPAB has remarkable power to affect the reimbursement of physicians in general and neuroradiologists in particular. ${ }^{1-3,7,19,20}$ This is particularly true in early implementation of the ACA, as hospitals and nursing homes are insulated from IPAB authority until 2020, leaving the physician providers in the crosshairs.

There have been a multitude of arguments for and against IPAB, including arguments for expansion on the one hand, and repeal on the other. Aaron ${ }^{17}$ considered the IPAB akin to Congress good deed for the country. He pursued a fascinating line of 
thinking, that is, that among the most important attributes of legislative statesmanship is self-abnegation-the willingness of legislators to abstain from meddling in matters they are poorly equipped to manage. The Federal Reserve Board embodies that virtue. Essentially, Congress recognized the temptation to use monetary policy for political ends and realized that it would, at times, prove irresistible. ${ }^{17}$ Consequently, to save themselves from this possibility, legislators created an organization whose funding and operations were largely beyond the reach of normal legislative controls. When one begins to process these concepts, one appreciates the fundamental similarities with the Federal Reserve in the construct of the IPAB.

Going even further, some advocates think it should be extended to include Medicaid, exchanges, and all types of payers. $^{21,22}$ In testimony before the House Budget Committee in 2011, Feder ${ }^{21}$ argued that given Medicare's relative success with cost controls, the expertise and authority of the IPAB should be applied to all payers - with a system wide spending target. Kathleen Sebelius, ${ }^{22}$ the Secretary of the US Department of Health and Human Services, stated that experts across the country, including independent economists and the Congressional Budget Office, believe that the IPAB is a needed safeguard.

In contrast, Holtz-Eakin ${ }^{23}$ is a detractor. He described the IPAB as a dramatic policy error that will fail to deliver meaningful reform to the Medicare program. In fact, he believes that it may well exacerbate existing reimbursement problems that already limit access to care for Medicare beneficiaries and stifle US-led medical innovation.

In a balanced perspective piece in the New England Journal of Medicine, Oberlander and Morrison ${ }^{11}$ note that the IPAB is hailed by supporters as the most important institutional change in the ACA, and a crucial component of health care cost containment. Specifically, many health policy analysts applaud the vision of a nonpartisan board, insulated from political pressures, that can formulate a more cohesive Medicare policy, analogous to the $\mathrm{Na}$ tional Institute for Health and Clinical Excellence of the National Health Service. ${ }^{15}$ These authors also report that supporters praise it as fail-safe, ensuring that growth in Medicare spending is moderated, regardless of congressional inaction. On the other hand, the authors also discuss the viewpoints of various IPAB critics. For instance, constraints prohibit the IPAB from making recommendations that raise revenues, increase cost sharing of Medicare beneficiaries, or restrict benefits and eligibility. It is expected to focus on savings from medical providers. ${ }^{11}$ A broad coalition of health care industry groups, fearful that the boards' proposals will result in reduced Medicare payments, fiercely opposes the IPAB. Furthermore, Republicans also view it as an instrument of rationing and bureaucratic intrusion into medicine.

One of the most telling points in the article by Oberlander and Morrison ${ }^{11}$ is their ironic observation that the first major milestone in the Board's operation passed with scant public notice, despite the political storm surrounding the IPAB. ${ }^{11}$ The April 2013 report of the Chief Actuary of the Center for Medicare \& Medicaid Services projected that Medicare spending per person will grow at an average rate of 1.15\% during 2011-2015, far below the target growth rate set by the ACA - the average of the consumer price index and the medical consumer price index. Conse- quently, this level of spending growth will not necessitate IPAB to propose reductions in Medicare reimbursement. If low Medicare spending growth continues, then the most controversial feature of the IPAB - congressional consideration of IPAB proposals under expedited procedures - will not come into play. It is, however, mandated that the target growth rate set by the ACA will be a rolling annual calculation, allowing the IPAB to act at the very hint of return of health care inflation.

The IPAB is supposed to begin its work in 2014, with recommendations due for the 2015 Medicare budget cycle. Of note, 3 years after the ACA's enactment, the President has yet to nominate a single member for the Board. ${ }^{11}$ Filling positions on the IPAB may itself be a monumental task, as these presidential appointments will require Senate approval—a daunting challenge given the current political climate.

It has been commonly noted that President Obama described the IPAB as "MedPAC on steroids." Considered in that vein, MedPAC might provide insight on how the regulatory and advisory roles of IPAB may affect neuroradiologists. Recent MedPAC proposals include the application of a multiple procedure payment reduction to the professional component of advanced imaging services, an approach that the American Society of Neuroradiology vehemently opposes along with the American College of Radiology, other imaging societies, and the American Medical Association. Page 40 of the June 2011 MedPAC report ${ }^{24}$ states, "CMS should calculate the payment reduction for second and subsequent professional component services performed in the same session by analyzing efficiencies in physician work associated with multiple services." In addition, and as a separate data point, we note that MedPAC has included specific information regarding radiologist compensation in its reports to Congress. Although we list only these 2 data points, it is reasonable to conclude from multiple data points that are beyond the scope of this article that MedPAC takes issue with the role that imaging plays in the global health care expenditure.

Neuroradiologists may hope that congressional review would deflect any intemperate IPAB recommendations and would never allow Congress to be marginalized by a nonlegislative independent board, given Medicare's popularity. Unfortunately, the track record of Congress with sequestration, the debt ceiling, and the multiyear failure to repeal the Sustainable Growth Rate formula argue against its ability to find a supermajority on any issue, particularly one promising revenue savings.

Arguably, the most compelling evidence marginalizing the potential power of the IPAB in the near future is the recent slowing in health care spending growth. The IPAB may be deprioritized until Medicare expenditures hit their legislatively defined targets.

\section{CONCLUSIONS}

The IPAB is a critical and controversial element of the ACA. Congress has ceded much of its own authority over Center for Medicare \& Medicaid Services spending to this independent board. Further, it has limited its own ability to affect the actions of the board through the fast-track process. The IPAB has the potential to significantly affect neuroradiologists' reimbursement. 


\section{ACKNOWLEDGMENTS}

We would like to thank Mike Morrow, American Society of Neuroradiology staff, for his review of this manuscript. We would also like to thank Cynthia Hynes for her assistance with the manuscript.

Disclosures: Joshua Hirsch—UNRELATED: Consultancy: CareFusion, Atrium, Comments: CareFusion: related to vertebral augmentation, 12 months; Atrium: singleday expert panel on disk disease, believe in last 36 months; Royalties: CareFusion, Comments: see above; Stock/Stock Options: Intratech, NFocus, Comments: Intratech: developmental stage ischemic stroke company; NFocus: ischemic and hemorrhagic stroke company. OTHER RELATIONSHIPS: I do not believe that any of the relationships described above have any impact on this article on the IPAB. David Rosman-UNRELATED: Board Membership: Optum Physician Advisory Board; Grants/Grants Pending: Harvey Neimann Health Policy Institute. Laxmaiah Manchikanti-Board Membership: American Society of Interventional Pain Physicians, Comments: unpaid position.

\section{REFERENCES}

1. Public Law No: 111-48: H.R. 3590. Patient Protection and Affordable Care Act. March 23, 2010

2. Manchikanti L, Hirsch JA. Patient Protection and Affordable Care Act of 2010: a primer for neurointerventionalists. J Neurointerv Surg 2012;4:141-46

3. Manchikanti L, Hirsch JA. Obamacare 2012: prognosis unclear for interventional pain management. Pain Physician 2012;15:E629-40

4. Meltzer CC. Summary of the Affordable Care Act. AJNR Am J Neuroradiol 2011;32:1165-66

5. Manchikanti L, Singh V, Caraway DL, et al. Proposed physician payment schedule for 2013: guarded prognosis for interventional pain management. Pain Physician 2012;15:E615-27

6. S. 668 (112th). Health Care Bureaucrats Elimination Act. March 29, 2011

7. Manchikanti L, Hirsch JA. The Independent Payment Advisory Board: impact on neurointerventionalists. J Neurointerv Surg 2012;4:468-72

8. Manchikanti L, Helm S, Hirsch JA. The evolution of the PatientCentered Outcomes Research Institute. J Neurointerv Surg 2012;4:157-62

9. Manchikanti L, Falco FJ, Benyamin RM, et al. The impact of comparative effectiveness research on interventional pain management: evolution from Medicare Modernization Act to Patient Protection and Affordable Care Act and the Patient-Centered Outcomes Research Institute. Pain Physician 2011;14:E249-82

10. Manchikanti L, Falco FJE, Benyamin RM, et al. Value-based interventional pain management: a review of Medicare national and local coverage determination policies. Pain Physician 2013;16: E145-80

11. Oberlander J, Morrison M. Failure to launch? The Independent Pay- ment Advisory Board's uncertain prospects. $N$ Engl $\mathrm{J} \mathrm{Med}$ 2013;369:105-07

12. Hartman M, Martin AB, Benson J, et al. National health spending in 2011: overall growth remains low, but some payers and services show signs of acceleration. Health Aff 2013;32:87-99

13. Centers for Medicare and Medicaid Services, Trustees Report shows reduced cost growth, longer Medicare solvency, May 31, 2013. http://www.cms.gov/Newsroom/MediaReleaseDatabase/ Press-Releases/2013-Press-Releases-Items/2013-05-31.html. Accessed June 25, 2013

14. Hirsch JA, Rosman DA, Liu RW, et al. Sustainable growth rate 2013: time for definitive intervention. J Neurointerv Surg 2013;5:382-86

15. National Institute for Health and Clinical Excellence (NICE). http://www.nice.org.uk/. Accessed June 25, 2013

16. Terry K. Should MedPAC be given authority over Medicare payments? BNET, June 4, 2009. http://www.bnet.com/blog/healthcarebusiness/should-medpac-be-given-authorityover-medicarepayments/414 Blog on CBS Interactive Business Network. Accessed June 25, 2013

17. Aaron HJ. The Independent Payment Advisory Board - Congress's “good deed.” N Engl J Med 2011;364:2377-79

18. H.R. 2015. Balanced Budget Act of 1997. P.L. 105e33. House Bill, 5 August 1997

19. Ebeler J, Neuman T, Cubanski J. The Independent Payment Advisory Board: a new approach to controlling Medicare spending. The Kaiser Family Foundation Program on Medicare Policy, April 13, 2011. http://kff.org/health-reform/issue-brief/the-independentpayment-advisory-board-a-new/. Accessed June 25, 2013

20. Ellenbogen PH. Independent Payment Advisory Board: bewaredanger! J Am Coll Radiol 2013;10:307

21. Testimony by Judith Feder, PhD, Professor and former Dean, Georgetown Public Policy Institute, and Urban Fellow Institute before the United States House of Representatives, Committee on the Budget RE: Medicare's future: An examination of the Independent Payment Advisory Board. July 12, 2011

22. Statement of Kathleen Sebelius, Secretary, U.S. Department of Health and Human Services, before the United States House of Representatives, Committee on the Budget RE: Medicare's future: An examination of the Independent Payment Advisory Board. July 12, 2011

23. Testimony by Douglas Holtz-Eakin, President, American Action Forum, before the United States House of Representatives, Committee on the Budget RE: Medicare's future: An examination of the Independent Payment Advisory Board. July 12, 2011

24. Medicare Payment Advisory Commission. Report to the Congress. Medicare and the Health Care Delivery System. Washington, DC: MedPAC. June 2012. http://www.medpac.gov/documents/Jun12 EntireReport.pdf. Accessed June 25, 2013 